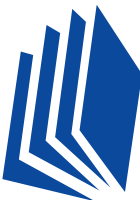

INNSPUB
International Journal of Biosciences | IJB |

ISSN: 2220-6655 (Print), 2222-5234 (Online)

http://www.innspub.net

Vol. 12, No. 1, p. 149-159, 2018

RESEARCH PAPER

OPEN ACCESS

\title{
Somatic embryogenesis enhancement of date palm cultivar Sewi using different types of polyamines and glutamine amino acid concentration under in-vitro solid and liquid media conditions
}

\author{
Maiada Mohammed El-Dawayati ${ }^{1}$, Hesham Sayed Ghazzawy ${ }^{* 1,2}$, Muhammad Munir ${ }^{2}$ \\ ${ }^{\prime}$ Central Laboratory for Date Palm Research and Development, Agriculture Research Center, \\ Giza, Egypt \\ ${ }^{2}$ Date Palm Research Center of Excellence, King Faisal University, A-Ahsa, Saudi Arabia
}

Key words: Date palm, Embryogenesis, Polyamines, Putrescine, Spermidine.

http://dx.doi.org/10.12692/ijb/12.1.149-159 $\quad$ Article published on January 12, 2018

\begin{abstract}
Date palm is traditionally propagated by ground off-shoots, which are in a limited number and varied with the cultivar. The production of date palm through tissue culture is well established due to the advantages of rapid clonal production, genetically uniformity and pathogen-free plants. The source explants are grown in a solid or liquid media. The media formulation and amendments play a vital role to establish a successful tissue culture protocol for explant regeneration and multiplication. Therefore, the rational of present study was to enhance somatic embryos induction of date palm cv. Sewi from embryonic callus during maturation stage by adding polyamines and glutamine amino acid concentrations in solid or liquid media. Two types of polyamines, putrescine and spermidine (each at $100 \mathrm{mg} \cdot \mathrm{L}^{-1}$ concentration) along with basic concentration of glutamine amino acid (B) (200 mg. $\mathrm{L}^{-1}$ ) or with the extra addition of glutamine concentration (EA) (100 mg.L $\mathrm{L}^{-1}$ ) were included in the study to develop micropropagation cycle of date palm plantlets. Explants cultured on solid media showed excellent embryonic callus whereas liquid media was best for somatic embryos induction. The quantitative observation indicated that maximum number of somaticembryos (32.33) were counted in liquid mediacontaining glutamine (EA) with putrescine. On the other hand, highest embryonic callus fresh weight was produced by the explants contained spermidinealone (5.49 g) and glutamine (EA) + spermidine (5.30 g) in solid media. It was concluded that putrescine with glutamine (EA) orits combination with spermidinealong with glutamine (B) in the solid or liquid in-vitromedia were the best for embryonic callus maturation to enhance the somatic embryogenesis of date palm cv. Sewi.
\end{abstract}

*Corresponding Author: Hesham Sayed Ghazzawy $₫$ hishamdates@hotmail.com 


\section{Introduction}

Sexual propagation for date palm (Phoenix dactylifera L.) does not consider for commercial purposes due to the high degree of genetic heterozygous progeny. Conventional vegetative propagation through offshoots is taken into account, which is hindered by slow growth rate and limited numbers (Faki, 2017). The production of date palm through in-vitro technique preferred widely for mass production of true-to-type plants (Aldaej et al., 2014; Shehata et al., 2014; Aleid et al., 2015). This technique is successfully adopted using shoot tip, lateral buds or inflorescences explants (Al-Khalifah and Shanavaskhan, 2012; Zayed and Abd El-Bar, 2015; Hussein et al., 2016).In-vitro date palm plantlets are produced by direct organogenesis or somatic embryogenesis (Sidky and El-Dawayati, 2012; Abd El-Bar and El-Dawayati, 2014; Ali et al., 2017). However, other in-vitropathway involved the induction of embryogenic callus prior to somatic embryogenesis (Al-Samir, 2015), which reveals a number of advantages over other in-vitro techniques. This indirect somatic embryogenesis technique allows the succession cultures of cell suspension or secondary embryos. Several studies have been conducted to optimize somatic embryogenesis of date palm by manipulating culture medium ingredients and physical conditions (Al-Khairy and Al-Bahrany, 2012; Baharan et al., 2015).

In order to extend the regeneration protocols, it is important to optimize the somatic embryogenesis conditions. In general, the developmental in-vitro pattern of cultured cells is mainly dependent on the choice of the nutritional components and growth regulators (Lima et al., 2012). Amino acids such as LGlutamine, Casein hydrolysate, L-Asparagine and Adenine are generally used as source of organic nitrogen in culture media (Zia et al., 2007). Growth of date palm callus tissue was significantly stimulated by the addition of amino acids specifically glutamine, which plays an important role in nitrogen assimilation as it is an intermediate in the transfer of ammonia into amino acids (Elmeer, 2013).
Polyamines also reported as growth regulators considered to be implicated in various physiological and developmental processes in plants. The most common types of polyamines are spermidine, spermine, and their diamine precursor, putrescine. Beneficial effects of polyamines on in-vitro regeneration and somatic embryogenesis were documented in several crops (Thiruvengadam et al., 2012; Mukherjee and Bandyopadhyay, 2014). Moreover, the promoter role of polyamines in the conversion of somatic embryos or shoot regeneration has been evidenced in several plant species (Górecka et al., 2014; Aydin et al., 2016). Hegazy and Aboshama (2010) suggested an efficient novel pathway in date palm tissue culture protocol by induction of direct somatic embryogenesis from bud tissues cultured in a medium containing through putrescine at $150 \mathrm{mg} . \mathrm{L}^{-1}$ along with plant growth regulators. Similarly, Ibrahim et al. (2014) reported that putrescine and salicylic acid significantly affected callus growth and somatic embryogenesis in date palm.

Therefore, keeping in view the significance of glutamine in the media components of date palm callus cultures and the importance of polyamines in somatic embryogenesis induction,, present research was conducted to observe the effect of two type of polyamines (putrescine and spermidine) in a solid or liquid media containing basic concentration of glutamine amino acid or with glutamine extra addition concentration on enhancing somatic embryos induction from embryonic callus during maturation stage of date palm cv. Sewi,in order to develop micropropagation cycle of date palm plantlets.

\section{Materials and methods}

Choice of explant and initial sterilization

Four-year-old, healthy female ground offshoots of date palm cv. Sewi were obtained from the orchard of government research center. The primary preparation of explants and sterilization method was conducted according to (El-Dawayatiy, 2017). 


\section{Explant material preparation}

Sequencing of indirect somatic embryogenesis protocol of date palm to obtain embryonic callus was conducted as follows:-sterilized shoot tip were sliced using the outer leaves primordia and shoot apex which divided longitudinally into 4 pieces then cultured on initiation stage medium for callus formation, which contains basic nutrient medium components as Murashige and Skoog (1962) basal nutrient medium supplemented with $\mathrm{NaH}_{2} \mathrm{PO}_{4} \cdot 2 \mathrm{H}_{2} \mathrm{O}$ (170 mg.L $\mathrm{L}^{-1}$ ), glutamine (200 mg.L $\mathrm{L}^{-1}$ ), adenine sulfate (40 mg. $\mathrm{L}^{-1}$ ), Thiamine hydrochloride (0.4 mg.L $\mathrm{L}^{-1}$ ), activated charcoal ( 2 g.L $\left.\mathrm{L}^{-1}\right)$, sucrose (30 g. $\left.\mathrm{L}^{-1}\right)$ with the addition of 2,4-D (10 mg. $\left.\mathrm{L}^{-1}\right)$ and $2 \mathrm{iP}\left(3 \mathrm{mg} . \mathrm{L}^{-1}\right)$ as growth regulators, for 3 subcultures with 6 weeks intervals. Continuously explants were transferred on the same components of previous basic nutrient medium with reducing the growth regulators to 3 mg.L $\mathrm{L}^{-1}$ 2, 4-D and 1 mg. $\mathrm{L}^{-1}$ 2iP for about 4-5 subcultures with 6 weeks intervals till the formation of friable callus, which collected to inoculate on basic nutrient medium supplemented with $0.5 \mathrm{mg} . \mathrm{L}^{-1} 2$, 4$\mathrm{D}$ and $2 \mathrm{mg} . \mathrm{L}^{-1}$ kinetin for 8 weeks as starting for maturation stage for callogenesis to induce somatic embryos. Creamy nodular embryonic callus were selected as explant material.

\section{Experiment treatments preparation}

Nutrient media components for maturation stage, as mentioned above, were used in two types of media i.e. solid (6 g.L $\mathrm{L}^{-1}$ agar) and liquid (without agar), two type of polyamines, putrescine and spermidine were added at $100 \mathrm{mg} . \mathrm{L}^{-1}$ with the combination of basic glutamine concentration (B) at $200 \mathrm{mg} . \mathrm{L}^{-1}$ in nutrient medium, or with extra addition of glutamine concentration (EA) at $100 \mathrm{mg} \cdot \mathrm{L}^{-1}$, that means nutrient medium with EA symbol have had total glutamine concentration of $300 \mathrm{mg} . \mathrm{L}^{-1}$ (Table 1). Embryonic callus weighing $0.5 \mathrm{~g}$ were slightly fragmented and placed on the two types of media i.e. solid and liquid media with studied treatments for 2 subcultures at 6 weeks intervals. Callus fresh weigh were determined at the end of each subculture in all treatments from the two type of media (omitting any developed somatic embryos). In all studied, treatments in solid and liquid media the number of induced white mature cotyledonary somatic embryos, which developed from embryonic callus were counted during 12 weeks of treatments. The liquid media treatments were kept on shaker (100 rpm) for 3 weeks then renewed for another 3 weeks by filtration through a sieve of $500 \mathrm{~mm}$ mesh size during the two subcultures of treatments. All differentiated somatic embryos, which resulted from all treatments, were transferred to resume their development until full plantlets received according to optimized protocol by El-Dawayatiy et al. (2014). The somatic embryos from liquid medium treatments were manifested in the form of hyperhy-dric tissues a desiccation procedure for 2 hours at laminar air flow (Sidky and Gadalla, 2014) before transferring to solid medium for continuing their conversion.

In all prepared media, $\mathrm{pH}$ was adjusted to 5.7 before the agar addition (with solid sterilized by autoclaving under pressure of $1.5 \mathrm{~kg} . \mathrm{cm}^{2}$ at $121^{\circ} \mathrm{C}$ for 20 minutes. Thereafter, the glass jars were transferred to the culture cabinet (laminar flow hood) and left to cool in a slant position until they were used for explant culture. Explants were cultured on MS media (solid and liquid) and incubated in dark at $25^{\circ} \mathrm{C} \pm 2$.

\section{Experimental design and statistical analysis}

The experiment was laid out on completely randomized design (CRD) with three replicates in each treatment. The data were statistically analyzed using GenStat version 18 (VSN International Ltd., UK).

\section{Results}

Callogenesis and embryogenesis of date palm $\mathrm{cv}$. Sewi in solid media

Data regarding embryonic callus fresh weight and number of somatic embryos in solid media showed statistically significant variation $(P \leq 0.05)$ when treated with polyamines alone and in combinations with glutamine (B) or glutamine (EA). Table 2 revealed that solid media contained spermidine with glutamine (B) produced maximum embryonic callus weight $(5.49 \mathrm{~g})$ followed by spermidine with glutamine (EA) $(5.30 \mathrm{~g})$. Control treatment with only glutamine (B) (4.30 g) and putrescine with glutamine (EA) (4.47 g) were statistically at par in the same media. 
However, minimum callus weight $(3.37 \mathrm{~g})$ was recorded when putrescine with glutamine (B) was used in solid media followed by putrescine + spermidine with glutamine (B) $(4.07 \mathrm{~g})$ treatment. Similarly, in the same type of media maximum number of somatic embryos (28) were counted in putrescine with glutamine (EA) (Fig. 1) and putrescine + spermidine combinations with glutamine (B). Solid media contained putrescine alone with glutamine (B) and control treatment produced 24.33 and 19.33 embryos respectively. Minimum number of somatic embryos were counted when solid media contained spermidine alone with glutamine (B) (11.67) followed by spermidine with glutamine (EA)(15.00).

Table 1. Polyamines and their combinations in solid and liquid media.

\begin{tabular}{|c|c|}
\hline Type of media & Polyamines \\
\hline \multirow[t]{6}{*}{ Solid media } & $200 \mathrm{mg} \cdot \mathrm{L}^{-1}$ Glutamine (B) Control \\
\hline & 100 mg.L $\mathrm{L}^{-1}$ Putrescine \\
\hline & 100 mg.L $L^{-1}$ Spermidine \\
\hline & 100 mg.L $L^{-1}$ Glutamine (EA) + 100 mg.L ${ }^{-1}$ Putrescine \\
\hline & 100 mg.L $L^{-1}$ Glutamine (EA) + 100 mg.L L $^{-1}$ Spermidine \\
\hline & 100 mg.L $L^{-1}$ Putrescine + 100 mg.L $L^{-1}$ Spermidine \\
\hline \multirow[t]{6}{*}{ Liquid media } & 200 mg.L. L $^{-1}$ Glutamine (B) Control \\
\hline & 100 mg.L L $^{-1}$ Putrescine \\
\hline & $100 \mathrm{mg} . \mathrm{L}^{-1}$ Spermidine \\
\hline & 100 mg.L L $^{-1}$ Glutamine (EA) + 100 mg.L L $^{-1}$ Putrescine \\
\hline & 100 mg.L. $\mathrm{L}^{-1}$ Glutamine (EA) + 100 mg.L $\mathrm{L}^{-1}$ Spermidine \\
\hline & 100 mg.L $L^{-1}$ Putrescine + 100 mg.L L $^{-1}$ Spermidine \\
\hline
\end{tabular}

B: Basic glutamine concentration (200 mg. $\mathrm{L}^{-1}$ ) in liquid and solid media

EA: Extra addition of $100 \mathrm{mg} . \mathrm{L}^{-1}$ of glutamine concentration along with glutamine (B) concentration (200 mg. $\left.\mathrm{L}^{-1}\right)$ i.e. $300 \mathrm{mg} \cdot \mathrm{L}^{-1}$ of Glutamine.

Callogenesis and embryogenesis of date palm $\mathrm{cv}$. Sewi in liquid media

Table 2 also showed a statistically significant difference $(P \leq 0.05)$ regarding embryonic callus fresh weight and number of somatic embryos in liquid media when treated with polyamines alone and in combinations with glutamine (B) or glutamine (EA). The liquid media having glutamine (B) alone as control treatment produced maximum embryonic callus weight $(5.07 \mathrm{~g})$ followed by spermidine alone with glutamine (B) $(4.60 \mathrm{~g})$ treatment. In the similar media, three treatments viz. putrescine with glutamine (EA) (3.49 g), putrescine + spermidine combination with glutamine (B)(3.24 g) and putrescine alone with glutamine (B) (3.03 g) behaved alike. However, minimum embryonic combination callus weight (1.18 g) was recorded when spermidine with glutamine (EA) was used in the liquid media.
Similarly, in the same type of media maximum number of somatic embryos (32.33) were counted in putrescine with glutamine (EA)combination (Fig. 2)followed byputrescine + spermidine with glutamine (B)treatment combinations (29.00). Liquid media contained putrescine with glutamine (B),control and spermidine with glutamine (EA) combination produced 23.33, 19.33 and 16.33 embryos respectively. Minimum number of somatic embryos were counted when liquid media had spermidine with glutamine (B)(12.67).

Combined analysis of callogenesis and embryogenesis potential of date palm $c v$. Sewi in solid and liquid media

The combined analysis of the data recorded in solid and liquid media indicated significant $(P \leq 0.05)$ difference regarding embryonic callus weight and 
number of somatic embryos (Table 2). Maximum embryonic callus weight was observed in solid media i.e spermidine with glutamine (B) $(5.49 \mathrm{~g})$ and spermidine with glutamine (EA) $(5.30 \mathrm{~g})$ followed bycontrol treatment with glutamine (B) alone application in the liquid media $(5.07 \mathrm{~g})$.

Table 2. Effects of different media formulation and polyamines on callogenesis and embryogenesis of date palm cultivar Sewi.

\begin{tabular}{|c|c|c|c|c|c|}
\hline \multicolumn{2}{|c|}{ Type of media / Polyamines } & $\begin{array}{c}\text { Callus weight } \\
\text { (g) }\end{array}$ & $\begin{array}{c}\text { No. of } \\
\text { embryos }\end{array}$ & $\begin{array}{c}\text { Callus } \\
\text { induction }\end{array}$ & \multirow{2}{*}{$\begin{array}{l}\text { Embryo } \\
\text { induction }\end{array}$} \\
\hline \multirow{6}{*}{$\begin{array}{l}\text { Solid } \\
\text { media }\end{array}$} & Glutamine (B) Control & $4.30^{\mathrm{b}}( \pm 0.21)$ & $19.33^{\mathrm{bc}}( \pm 1.77)$ & $\overline{+++}$ & \\
\hline & Putrescine & $3.37^{c}( \pm 0.09)$ & $24.33^{\mathrm{b}}( \pm 2.34)$ & ++ & +++ \\
\hline & Spermidine & $5.49^{\mathrm{a}}( \pm 0.41)$ & $11.67^{\mathrm{c}}( \pm 1.45)$ & +++ & + \\
\hline & Glutamine (EA) + Putrescine & $4.47^{\mathrm{b}}( \pm 0.37)$ & $28.00^{\mathrm{a}}( \pm 4.05)$ & +++ & +++ \\
\hline & Glutamine (EA) + Spermidine & $5 \cdot 30^{\mathrm{a}}( \pm 0.10)$ & $15.00^{\mathrm{c}}( \pm 1.73)$ & +++ & ++ \\
\hline & Putrescine + Spermidine & $4.07^{\text {bc }}( \pm 0.07)$ & $28.00^{\mathrm{a}}( \pm 3.06)$ & ++ & +++ \\
\hline \multirow{6}{*}{$\begin{array}{l}\text { Liquid } \\
\text { media }\end{array}$} & Glutamine (B) Control & $5.07^{\mathrm{a}}( \pm 0.30)$ & $19.33^{\text {bc }}( \pm 2.97)$ & +++ & ++ \\
\hline & Putrescine & $3.03^{\mathrm{c}}( \pm 0.14)$ & $23 \cdot 33^{\mathrm{b}}( \pm 0.88)$ & ++ & ++ \\
\hline & Spermidine & $4.60^{\mathrm{b}}( \pm 0.21)$ & $12.67^{\mathrm{c}}( \pm 1.45)$ & +++ & + \\
\hline & Glutamine (EA) + Putrescine & $3.49^{\mathrm{c}}( \pm 0.29)$ & $32.33^{\mathrm{a}}( \pm 1.45)$ & ++ & +++ \\
\hline & Glutamine (EA) + Spermidine & $1.18^{\mathrm{d}}( \pm 0.33)$ & $16.33^{c}( \pm 0.88)$ & + & + \\
\hline & Putrescine + Spermidine & $3.24^{\mathrm{c}}( \pm 0.42)$ & $29.00^{\mathrm{a}}( \pm 2.08)$ & ++ & +++ \\
\hline \multicolumn{2}{|l|}{ SED } & 0.387 & 3.25 & & \\
\hline \multicolumn{2}{|l|}{ LSD } & 0.802 & 6.74 & & \\
\hline \multicolumn{2}{|c|}{ Probability } & $<0.001$ & $<0.001$ & & \\
\hline
\end{tabular}

Data in each column higher than LSD value are significantly different at $P<0.001$.

SED is the standard error of difference between two means in each column.

Standard error between replicates within sample are in parenthesis.

$+=$ poor,$++=$ medium and $+++=$ Excellent .

There was non-significant difference among these three treatments. However, minimum embryonic callus weight was estimated in liquid media containing spermidine with glutamine (EA) (1.18 g).

Among other treatments, control (4.30 g), putrescine + spermidine with glutamine (B) (4.07 g), putrescine with glutamine (EA) (4.47 g) in solid media and spermidine with glutamine (B) (4.60 g) in liquid media behaved alike. On the other hand, maximum number of somatic embryos were counted in liquid media containing putrescine with glutamine (EA) $(32.33 \mathrm{~g})$ and putrescine + spermidine with glutamine (B) (29.00 g) followed byputrescine + spermidine with glutamine (B) and putrescine with glutamine (EA) (28.0o g each) combinations in solid media.
There was non-significant difference among these four combinations. Minimum number of embryos were calculated in solid media having spermidine with glutamine (B)(11.67 g) and spermidine with glutamine (EA) (15.00 g) followed by spermidine with glutamine (B)(12.67 g) and spermidine with glutamine (EA) (16.33 g) in liquid media. Putrescine with glutamine (B) in solidmedium (24.33 g) and liquid media (23.33 g) and control treatment in solid and liquid media (19.33 $\mathrm{g}$ each) were statistically at par. Table 2 also indicated the strength of embryonic callus and embryo induction. Callus induction in solid media containing glutamine (B) alonecontrol treatment, putrescine with glutamine (EA), spermidine with glutamine (EA) and spermidine with glutamine (B) and in liquid media spermidine with 
glutamine (B) were ranked as excellent. Similarly, the strength of embryo induction was excellent in solid media having putrescine with glutamine (B), putrescine with glutamine (EA), putrescine + spermidine with glutamine (B), and the liquid media containing putrescine with glutamine (EA) and putrescine + spermidine with glutamine (B).

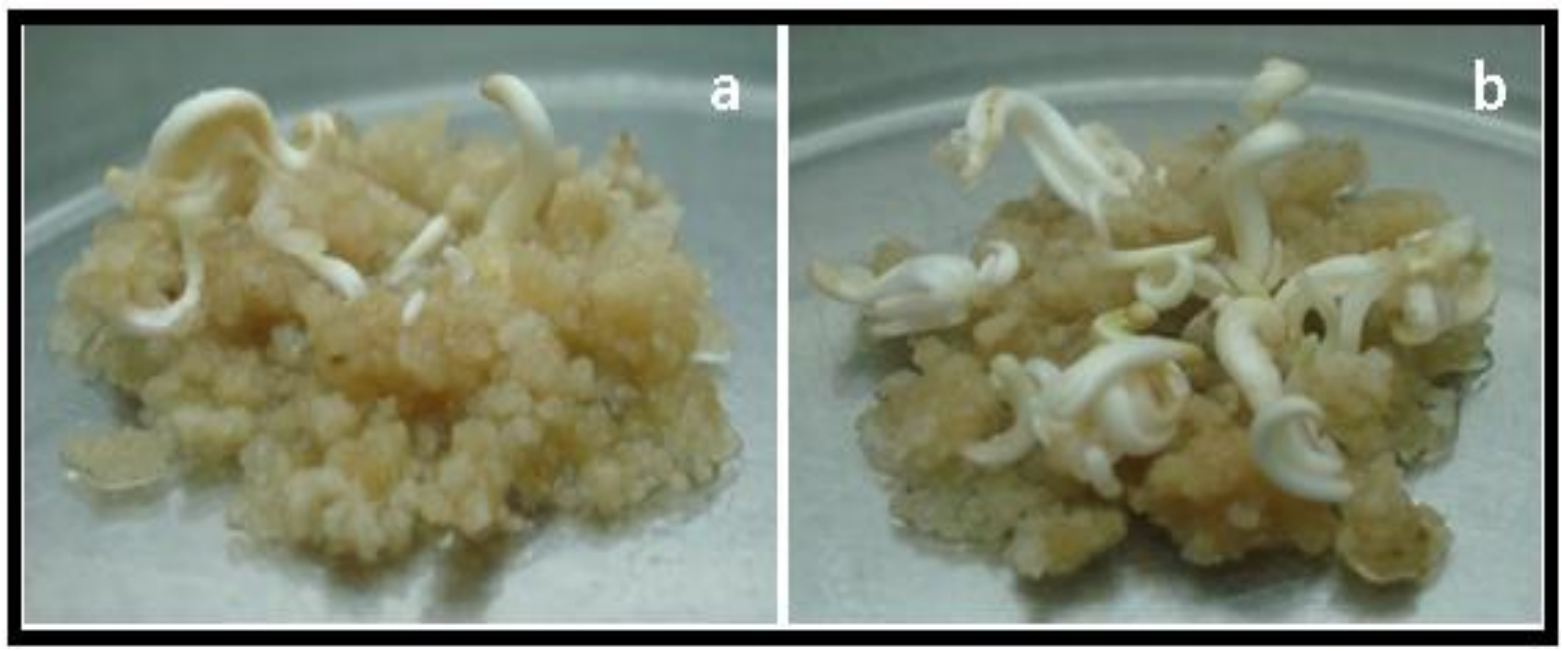

Fig. 1. (a) The addition of putrescine (100 mg. $\left.\mathrm{L}^{-1}\right)+$ glutamine (EA) (300 mg.L-1) treatment under solid medium was the best for somatic embryos induction from embryonic callus date palm cv. Sewi. (b) The addition of spermidine (100 mg. $\left.\mathrm{L}^{-1}\right)$ + glutamine (B) (200 mg. $\mathrm{L}^{-1}$ ) treatment under solid medium was the poorest combination for somatic embryos induction from embryonic callus date palm cv. Sewi.

\section{Discussion}

In present study, we have investigated the effect of two type of polyamines, putrescine and spermidine alone in a solid or liquid media containing a basic concentration of glutamine amino acid (B) (200 mg.L1) or combined in the similar type of media (solid or liquid) with an extra addition of $100 \mathrm{mg} . \mathrm{L}^{-1}$ glutamine
(EA) under in-vitro culture to enhance somatic embryos induction from embryonic callus during maturation stage of date palm cv. Sewi. The production of callus is the primary step in date palm in-vitro culture, which leads to either embryogenesis to organogenesis.

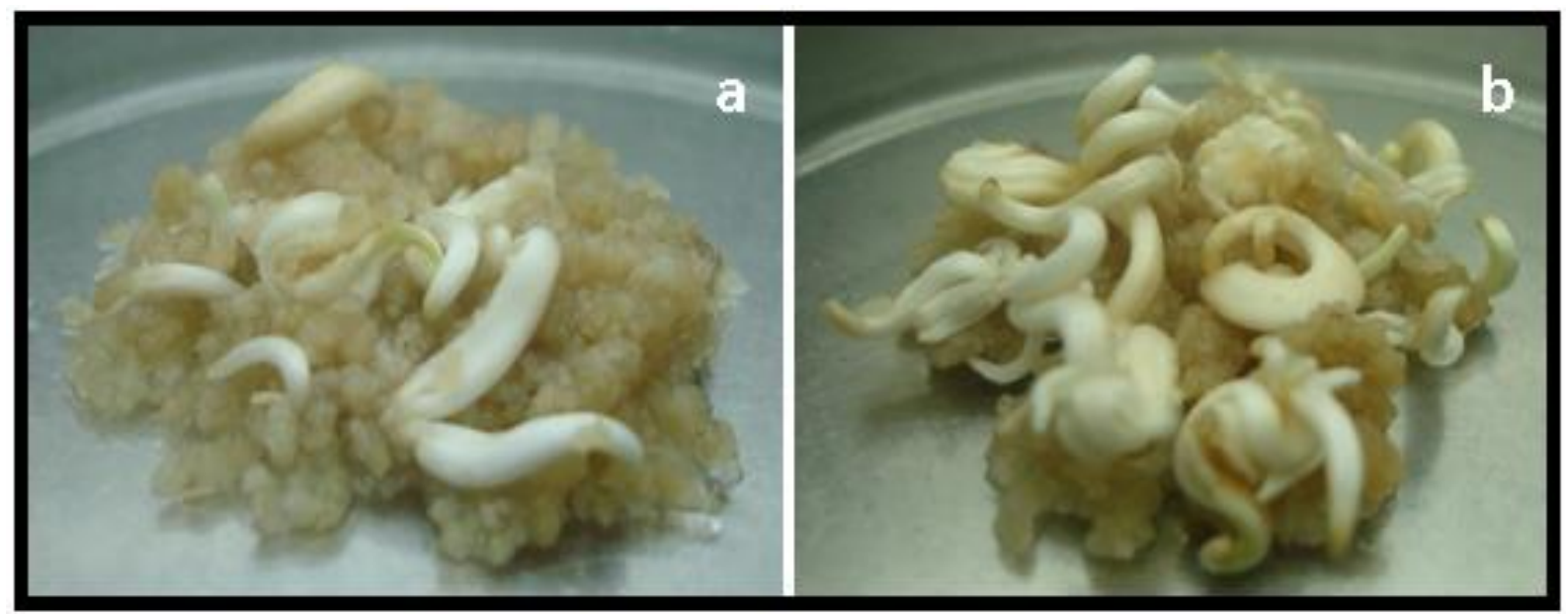

Fig. 2. (a) The addition of putrescine (100 mg. $\left.\mathrm{L}^{-1}\right)+$ glutamine (EA) (300 mg. $\left.\mathrm{L}^{-1}\right)$ treatment under liquid medium was the best for somatic embryos induction from embryonic callus of date palm cv. Sewi. (b) The addition of spermidine (100 mg. $\left.\mathrm{L}^{-1}\right)+$ glutamine (B) (200 mg. $\mathrm{L}^{-1}$ ) treatment under liquid medium was the poorest combination for somatic embryos induction from embryonic callus date palm cv. Sewi. 
The efficiency of callogenesis and embryogenesis is influenced by many factors such as plant hormones, type of media, in-vitro condition, polyamines, etc. (Datta, 2005; Bhojwani and Dantu, 2010). Our findings indicated that the overall average callus weight was highest in solid media (4.50 g) as compared to liquid media (3.44 g) with a standard deviation of \pm 0.75 . Contradictorily, an overall average number of embryos were slightly lesser in solid media (21.06) than liquid media (22.17 g) with a standard deviation of \pm 0.79 , which was in harmony with Sidky and El-Dawyati (2012) who reported that the average number of mature somatic embryos was increased significantly when liquid nutrient culture medium was used for culturing embryonic callus of date palm inflorescence instead of solid culture medium. Some researchers proposed the use of exogenous polyamines during the processes leading to in-vitro plant and callus formation (Debiasi et al., 2007). Present results indicated that the use of glutamine at high concentration (EA) combined with polyamines enhanced maturation of somatic embryos from embryonic callus of date palm (Fig. 3).

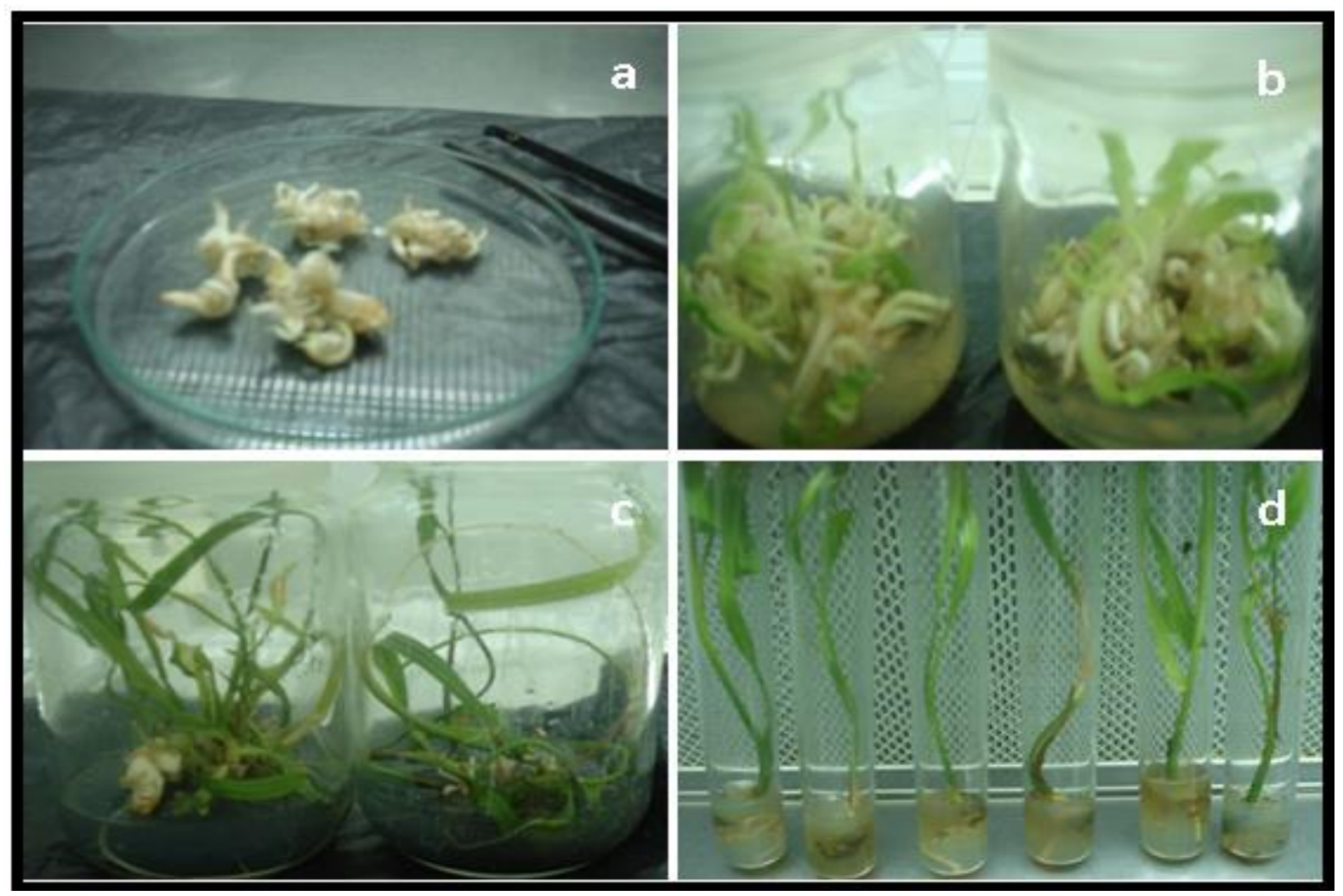

Fig. 3. The addition of putrescine $\left(100 \mathrm{mg} \cdot \mathrm{L}^{-1}\right)+$ glutamine (EA) (300 mg. $\left.\mathrm{L}^{-1}\right)$ : (a) well germinated somatic embryos, (b) shoots formation and multiplication, (c) shoots elongation and (d) well rooted plantlets ready to transfer for acclimatization.

These findings are in line with (Ageel and Elmeer, 2011) who reported that date palm culture media with organic nitrogen, especially high concentrations of glutamine improved callus induction and rate of growth and stimulated embryogenesis. However, the extra addition of amino acids such as glutamine significantly stimulated growth of plant callus tissue, since in plant tissue cultures organic nitrogen was a growth-limiting factor.
Thus, the culture lag phase was decreased by the inclusion of glutamine, which indicated that glutamine plays an important role in nitrogen assimilation, as it is an intermediate in the transfer of ammonia into amino acids (Ageel and Elmeer, 2011).

Results of present study showed that addition of glutamine significantly enhanced embryogenesis in date palm cv. Sewi. Glutamine is one of the most 
readily available amino acids for use as an energy source for many rapidly dividing cell types under invitro condition. It is an efficient precursor of the releasable glutamate and gamma-aminobutyric acid (GABA) pools (Elmeer, 2013). On the other hand, it is the precursor of arginine and is metabolized via acetylated derivatives to ornithine, citrulline and argininosuccinate in a nine-step process (Slocum, 2005), where arginine and ornithine may also act as precursors of polyamines (Alca'zar et al., 2006). Thus, it can be suggested that elevated glutamine concentration may induced the endogenous polyamines, which stimulatedthe somatic embryo induction from embryonic callus of date palm cv. Sewi. Similarly, the importance of exogenous polyamines in improving the somatic embryogenesis is well-reported. Previous studies suggested that polyamines implicate in enhancing somatic embryogenesis process, as Steiner et al. (2007) observed that exogenous application of polyamines in the embryogenic culture of Araucaria angustifolia increased the endogenous IAA and ABA levels, showing a direct relationship between polyamines levels and ABA accumulation, which further improve somatic embryogenesis, especially during the maturation phase.

The findings of present study indicated that putrescine with glutamine (in liquid and solid media), and with spermidine (in solid media) produced highest number of embryos and were statistically alike. Polyamines also known to inhibit ethylene biosynthesis, which considered as a potent inhibitor of embryogenesis and morphogenesis (Kumar et al., 2008; Faust and Wang, 2010). S-adenosylmethionine (SAM) is the common precursor for both polyamines and ethylene. It is evident that there is competition for SAM between the biosynthetic pathways of polyamines and ethylene (Minocha et al., 1990) and this may be of the reasons for enhanced somatic embryogenesis by the addition of polyamines in the media. Hegazy and Aboshama (2010) induced direct somatic embryogenesis from bud tissues of date palm through putrescine. Similarly, Kumar et al. (2004) applied putrescine and spermidine as an addition to the induction medium of cucumbers, whereas
Górecka et al. (2014) reported that the addition of putrescine, spermidine, and a mixture of the both to the induction medium had a beneficial effect on the number of embryos in Daucus carota. The results of present study are in line with the above-mentioned studies where the addition of polyamines enhanced somatic embryos formation.

\section{Conclusion}

It can be concluded from the present findings that the addition of putrescine in combination with higher concentration of glutamine (EA) has positive embryogenetic potential in date palm cv. Sewi grown in solid and liquid media.

The best callogenetic response was obtained when spermidine alone or in combination with higher concentration of glutamine (EA) in solid media was used. Higher concentration of glutamine (EA) combined with putrescine in the liquid media produced maximum number of excellent somatic embryos (32.33) with good callus induction. Statistically similar results were observed when the same treatment combination was added in solid media with an excellent callus induction and somatic embryos (28). All somatic embryos continued their developmental stages until the production of healthy plantlets, which were fully capable to transfer to the control room for acclimatization. The promoter effect of high concentration of glutamine (EA) and polyamines (putrescine) as organic nitrogen source were preferred for somatic embryos induction during maturation stage in order to develop micropropagation cycle of date palm plantlets.

\section{References}

Abd El-Bar OH, El Dawayati MM. 2014. Histological changes on regeneration in-vitro culture of date palm (Phoenix dactylifera) leaf explants. Australian Journal of Crop Science 8, 848-855.

Ageel S, Elmeer K. 2011. Effects of casein hydrolysates and glutamine on callus and somatic embryogenesis of date palm (Phoenix dactylifera L.). New York Science Journal 4, 121-125. 
Alca'zar R, Marco F, Cuevas JC, Patron M, Ferrando A, Carrasco $\mathbf{P}$, Tiburcio AF, Altabella T. 2006. Involvement of polyamines in plant response to abiotic stress. Biotechnology Letters 28, 1867-1876.

https://doi.org/10.1007/s10529-006-9179-3

Aldaej M, AlturkiS, ShahataW, GhazzawyH. 2014. Effect of Potassium Nitrate on Antioxidants Production of Date Palm (Phoenix dactylifera L.) in vitro. Pakistan Journal of Biological Sciences12, 1209-1218.

http://dx.doi.org/10.3923/pjbs.2014.209.1218

Aleid SM, Al-Khayri JM, Al-Bahrany AM. 2015. Date palm status and perspective in Saudi Arabia. In: Al-Khayri JM, Jain SM, Johnson DV, Eds. Date palm genetic resources and utilization, Springer, Dordrecht, p. 49-95.

http://dx.doi.org/10.1007/978-94-017-9707-8

Ali KM, Sabbour AM, Khalil MK, Aly AS, ElDin AFZ. 2017. In-vitro morphogenesis of direct organs in date palm (Phoenix dactylifera L.) cv. Siwy. International Journal of Advanced Agricultural Science and Technology 4, 1-12.

Al-Khairy J, Al-Bahrany AM. 2012. Effect of abscisic acid and polyethylene glycol on the synchronization of somatic embryo development in date palm (Phoenix dactylifera L). Biotechnology 11, 318-325.

http://dx.doi.org/10.3923/biotech.2012.318.325

Al-Khalifah NS, Shanavaskhan AE. 2012. Micropropagation of Date Palms. Asia-Pacific Consortium on Agricultural Biotechnology and Association of Agricultural Research Institutions in the Near East and North Africa, p. 54.

Al-Samir E, Al-Utbi S, Abass M. 2015. Phytotoxic effect of 2,4-D and dicamba on date palm (Phoenix dactylifera L.) tissue cultures at initiation stage. Advances in Agriculture and Botanics 7, 96-108.

Aydin M, Pour AH, Haliloğlu K, Tosun M. 2016. Effect of polyamines on somatic embryogenesis via mature embryo in wheat. Turkish Journal of Biology 40, 1178-1184. http://dx.doi.org/10.3906/biy-1601-21
Baharan E, Pour P, Mohammadi E, Shahbaziand S, Hosseini Z. 2015. Effects of some plant growth regulators and light on callus induction and explants browning in date palm (Phoenix dactylifera L.) in-vitro leaves culture. Iranian Journal of Plant Physiology 5, 1473-1481.

Bhojwani SS, Dantu PK. 2010. Haploid plants. In: Davey MR, Anthony P, Eds. Plant cell culture: Essential methods. Wiley-Blackwell, Chichester, United Kingdom, 61-67 P.

Datta SK. 2005. Androgenic haploids: factors controlling development and its application in crop improvement. Current Science 89, 1870-1878.

Debiasi C, Fraguas CB, Lima GPP. 2007. Study of polyamines in the morphogenesis in-vitro of Hemerocallis sp., Ciencia Rural 37, 1014-1020. http://dx.doi.org/10.1590/So103847820070004000 15

El-Dawayati MM, Zayed Z, Sidky R. 2014. An efficient protocol for the in-vitro multiplication of date palm (Phoenix dactylifera L.) cv. Gondela to optimize shooting stage. Egyptian Journal of Applied Sciences 29, 318-332.

El-Dawayati MM. 2017. In-vitro conservation of date palm shoot-tip explants and callus cultures under minimal growth conditions. In: Al-Khayri JM, Jain SM, Johnson DV, Eds. Date Palm Biotechnology Protocols, Volume II: Germplasm Conservation and Molecular Breeding, Springer, New York, 49-58 P.

Elmeer KS. 2013. Factors regulating somatic embryogenesis in plants. In: Junaid A, Srivastava P, Sharma M, Eds. Somatic embryogenesis and gene expression, New Delhi, India, 57-82 P.

Faust M, Wang SY. 2010. Polyamines in horticulturally important plants. In: Janick J, Ed. Horticultural Reviews, Volume 14, John Willy \& Sons, Inc. Canada, 335-353 P. 
Fki L, Kriaa W, Nasri A, Baklouti E, Chkir O, Masmoudi R, Rival A, Drira N. 2017. Indirect somatic embryogenesis of date palm using juvenile leaf explants and low 2,4-D concentration. In: AlKhayri JM, Jain SM, Johnson DV, Eds. Date Palm Biotechnology Protocols, Volume II: Germplasm Conservation and Molecular Breeding, Springer, New York, 99-106 P.

Górecka K, Kiszczak W, Krzyżanowska D, Kowalska U, Kapuścińska A. 2014. Effect of polyamines on in-vitro anther cultures of carrot (Daucus carota L.). Turkish Journal of Biology $\mathbf{3 8}$, 593-600.

http://dx.doi.org/10.3906/biy-1403-29

Hegazy AE, Aboshama HM. 2010. An efficient novel pathway discovered in date palm micropropagation. Acta Horticulturae 882, 167-176. http://dx.doi.org/10.1766o/ActaHortic.2010.882.18

Hussein J, Khaun A, Abdulrahman D. 2016. Improving the germination of somatic embryos in date palm Berhi cultivar in-vitro. International Journal of Agronomy and Agricultural Research 8, 17-23.

Ibrahim KM, Khierallah HSM, Hussein NH. 2014. Callus growth and somatic embryogenesis as affected by putrescine and salicylic acid in date palm Bream cv. In: Zaid A, Alhadrami G, Eds. Proceedings of the Fifth International Date Palm Conference, Khalifa International Date Palm Award, Abu Dhabi, UAE, 225-229.

\section{Kumar HG, Ravishankar BV, Murthy HN.}

2004. The influence of polyamines on androgenesis of Cucumis sativus L. European Journal of Horticultural Science 69, 201-205.

Kumar V, Giridhar P, Chandrashekar A, Ravishankar GA. 2008. Polyamines influence morphogenesis and caffeine biosynthesis in in-vitro cultures of Coffea canephora. Acta Physiologiae Plantarum 30, 217-223.

http://dx.doi.org/10.1007/s11738-007-0110-x
Lima GP, Campos RS, Willadino LG, Terezinha JR, Vianello F. 2012. Polyamines, gelling agents in tissue culture, micropropagation of medicinal plants and bioreactors. In: Leva A, Rinaldi L, Eds. Recent advances in plant in-vitro culture. In Tech, p. 165-185.

http://dx.doi.org/10.5772/52760

Minocha SC, Robie CA, Khan AJ, Papa N, Samuelsen AI. 1990. Polyamine and ethylene biosynthesis in relation to somatic embryogenesis in carrot (Daucus carota) cell cultures. In: Flores HE, Artcca RN, Shannon JC, Eds. Polyamines and Ethylene: Biochemistry, Physiology and Interactions. American Society for Plant Physiology, Rockville, MD, p. 339-342.

Mukherjee A, Bandyopadhyay A. 2014. Inducing somatic embryogenesis by polyamines in medicinally important Clerodendrum indicum L. International Journal of Current Microbiology and Applied Sciences 3, 12-26.

Murashige T, Skoog F. 1962. A revised medium for rapid growth and bioassays with tobacco tissue cultures. Physiologia Plantarum 15, 473-479.

http://dx.doi.org/10.1111/j.13993054.1962.tbo8052.x

Sidky R, El-Dawyati M. 2012. Proliferation of female inflorescence explants of dare palm. Annals of Agricultural Sciences 57, 161-165.

https://doi.org/10.1016/j.aoas.2012.08.010

Shahata W, Aldaej M, AlturkiS, Ghazzawy $\mathbf{H}$. 2014. Effect of Ammonium Nitrate on Antioxidants Production of Date Palm (Phoenix dactylifera L.) in vitro. Biotechnology3, 116-125.

http://dx.doi.org/10.3923/biotech.2014.116.125

Sidky RA, Gadalla EG. 2014. Somatic embryogenesis in Phoenix dactylifera maturation, germination and reduction of hyperhydricity during embryogenic cell suspension culture. In: Zaid A, Alhadrami G, Eds. Proceedings of the Fifth International Date Palm Conference, Khalifa International Date Palm Award, Abu Dhabi, UAE, 185-192. 
Slocum RD. 2005. Genes, enzymes and regulation of arginine biosynthesis in plants. Plant Physiology and Biochemistry 43, 729-745.

http://dx.doi.org/10.1016/j.plaphy.2005.06.007

Steiner N, Santa-Catarina C, Silveira V, Floh

E, Guerra M. 2007. Polyamine effects on growth and endogenous hormones levels in Araucaria angustifolia embryogenic cultures. Plant Cell, Tissue and Organ Culture 89, 55-62.

http://dx.doi.org/10.1007/s11240-007-9216-5

Thiruvengadam M, Chung I, Chun S. 2012. Influence of polyamines on in-vitro organogenesis in bitter melon (Momordica charantia L.). Journal of Medicinal Plant Research 6, 3579-3585.

http://dx.doi.org/10.5897/JMPR12.246
Zayed EMM, Abd Elbar OH. 2015. Morphogenesis of immature female inflorescences of date palm invitro. Annals of Agricultural Science 6o, 113-120. https://doi.org/10.1016/j.aoas.2015.04.003

Zia M, Mannan A, Chaudhary MF. 2007. Effect of growth regulators and amino acids on artemisinin production in the callus of Artemisia absinthium. Pakistan Journal of Botany 39, 799-805. 